\title{
Sol-gel deposited ceria thin films as gate dielectric for CMOS technology
}

\author{
ANIL G KHAIRNAR and ASHOK M MAHAJAN* \\ Department of Electronics, North Maharashtra University, Jalgaon, 425 001, India
}

MS received 10 January 2012; revised 7 April 2012

\begin{abstract}
In this work, cerium oxide thin films were prepared using cerium chloride heptahydrate, ethanol and citric acid as an additive by sol-gel spin-coating technique and further characterized to study the various properties. Chemical composition of deposited films has been analysed by FTIR which shows existence of $\mathrm{CeO}_{2}$. The samples have been optically characterized using ellipsometry to find refractive index of $2 \cdot 18$ and physical thickness which is measured to be $5.56 \mathrm{~nm}$. MOS capacitors were fabricated by depositing aluminum (Al) metal using the thermal evaporation technique on the top of $\mathrm{CeO}_{2}$ thin films. Capacitance-voltage measurement was carried out to calculate the dielectric constant, flat-band voltage shift of $18 \cdot 92,0 \cdot 3-0.5 \mathrm{~V}$, respectively and conductance-voltage study was carried out to determine the $D_{\text {it }}$ of $1.40 \times 10^{13} \mathrm{eV}^{-1} \mathrm{~cm}^{-2}$ at $1 \mathrm{MHz}$.
\end{abstract}

Keywords. High- $k$; $\mathrm{CeO}_{2}$; gate dielectric; sol-gel; FTIR; XRD; CV.

\section{Introduction}

In the current era of nanotechnology, the semiconductor device industries require high dielectric (high- $k$ ) materials for gate dielectric applications in advance CMOS circuits. The different dielectric layers are being used as gate oxide in MOSFETs, as capacitor to store charge in memory devices and as an insulator in back-end interconnects (Rathee et al 2010). Earlier, the $\mathrm{SiO}_{2}$ was the most promising dielectric material of choice for all these applications (Houssa et al 2006). The semiconductor roadmap following Moore's law is responsible for an exponential decrease of minimum feature size of devices. But, in order to follow Moore's law, the current trends are use of nanoelectronics and technological research towards the scaling down of devices to smaller physical dimensions (Guha and Narayanan 2009). The decrease in device feature size offers increased speed, low power consumption and low cost because of the increased density of devices per wafer as per ITRS. This size reduction presents challenges for the various $\mathrm{SiO}_{2}$ applications due to the quantum mechanical effects as the thickness of conventional $\mathrm{SiO}_{2}$ gate insulators is reduced just to a few atomic layers, electrons can tunnel directly through the films and cause leakage currents resulting in increase of power dissipation to unacceptable levels, heat becomes critical issue and reduces device reliability (Gusev 2006).

In order to maintain low power consumption performance of CMOS transistors, high- $k$ gate dielectrics must be employed to replace conventional $\mathrm{SiO}_{2} / \mathrm{SiON}$ as the scale of the channel length goes down to sub-100 nm feature size. Alternative gate dielectric needs the stringent requirements including high permittivity, thermal stability, high level film

\footnotetext{
*Author for correspondence (ammahajan@nmu.ac.in)
}

and interface quality, processing and materials compatibility with fabrication of CMOS devices and long-term reliability for practical replacement of $\mathrm{SiO}_{2} / \mathrm{SiON}$ (Wilk et al 2001). Many materials have been investigated as candidates for this replacement. Among all the high- $k$ dielectrics, amorphous metal oxides, such as unary metal oxide of $\mathrm{Al}_{2} \mathrm{O}_{3}$ (Gusev et al 2000), $\mathrm{CeO}_{2}$ (Kang et al 1998; Inoue et al 1999), $\mathrm{HfO}_{2}$ (Lee et al 2000; Wilk et al 2000) and $\mathrm{ZrO}_{2}$ (Zhong et al 2001) and binary systems of $\left(\mathrm{Y}_{2} \mathrm{O}_{3}\right)_{x}\left(\mathrm{ZrO}_{2}\right)_{1-x}$ (yttriastabilized $\mathrm{ZrO}_{2}$ ) (Wang et al 2000), $\mathrm{LaAlO}_{3}$ (Xiang et al 2003) and $\left(\mathrm{HfO}_{2}\right)_{x}\left(\mathrm{Al}_{2} \mathrm{O}_{3}\right)_{1-x}$ (Yu et al 2002), have been shown to be the most promising high- $k$ gate dielectrics due to their high dielectric constant, excellent thermal stability and good compatibility with modern electronics processing techniques.

Recently, the rare earth cerium oxide $\left(\mathrm{CeO}_{2}\right)$ has been reported to be a potentially promising alternative gate dielectric to replace the conventional $\mathrm{SiO}_{2}$ with a lot of potential advantages (Quah et al 2010, 2011; Lim et al 2011) for CMOS applications such as: high-dielectric constant $(k \sim$ $26)$, large bandgap $(\sim 5.5 \mathrm{eV})$, fluorite structure with very small lattice mismatch of $\sim 0.35 \%$, high thermodynamic stability and good interface with Si substrate. The film's structure and interface properties depend upon deposition processes. Several deposition techniques have been reported in literature for the preparation of $\mathrm{CeO}_{2}$ films on $\mathrm{Si}$ for CMOS devices, including sputtering (Wang et al 2001), vacuum evaporation (Inoue et al 1990), MBE (Joumori et al 2004), PLD (Karakaya et al 2006), MOCVD (Ami and Suzuki 1998), and E-beam evaporation (Inoue et al 1999), etc. All these techniques require high temperature treatments which usually induces a deterioration of the device performance and reliability. Therefore, for silicon-based nanoelectronics device fabrication, low temperature processes are strongly desired. 
The present paper is concerned with the deposition of spin-coated $\mathrm{CeO}_{2}$ films prepared using an ethanolic precursor sol containing citric acid as an additive. The deposited $\mathrm{CeO}_{2}$ films have been characterized by XRD, FTIR and ellipsometer for microstructural, chemical and optical properties and also capacitance-voltage $(C-V)$ measurement is carried out for studying some of the electrical properties. This work attempts to explore the properties of ceria for gate dielectric applications in CMOS devices. Experimental details are presented in the second section and the results are discussed in the third section of the paper whereas the fourth section concludes the paper.

\section{Experimental}

Sol-gel derived $\mathrm{CeO}_{2}$ films were deposited on commercially available $p$-type $\mathrm{Si}\left(\begin{array}{lll}1 & 0 & 0\end{array}\right)$ wafers with resistivity $\sim 10-20 \Omega-\mathrm{cm}$. The silicon substrates were cleaned using trichloro-ethylene (Himedia), acetone and methanol with $5 \mathrm{~min}$ heat treatment, respectively, followed by rinse in deionized water (DI). Ceria sol was prepared by dissolving $2.5 \mathrm{~g}$ cerium chloride heptahydrate $\left(\mathrm{CeCl}_{3} \cdot 7 \mathrm{H}_{2} \mathrm{O}\right.$, makeHimedia) as source of ceria in $30 \mathrm{ml}$ ethanol, followed by the addition of citric acid (Fisher Scientific) precursor in 1:1.0 mole ratio. Then solution was spin coated (Milman-2000S) at a spinning speed of $6000 \mathrm{rpm}$ for $30 \mathrm{~s}$ on Si. These spincoated films were heat treated for $5 \mathrm{~min}$ in air in an electric furnace at $400{ }^{\circ} \mathrm{C}$. The metal and substrate contacts were formed by depositing aluminum metal using the thermal evaporation (Hind-HIVAC) system for MOS capacitor fabrication. The native oxide at the backside of $\mathrm{Si}$ was removed by the hydrofluoric acid followed by rinsing in deionized water and then the bulk contact of Al was formed by using thermal evaporation system at the backside of Si. The electrical connections are taken from top metal electrode and backside substrate contact. The deposited films were characterized by ellipsometer (Philips SD-1000), Fourier transform infrared spectroscopy (FTIR) and X-ray diffraction. Capacitance-voltage $(C-V)$ and conductance-voltage $(G-V)$ measurements have been carried out using (Agilent $4284 \mathrm{~A}$ ) LCR meter. Electrical dielectric constant and density of interface traps $\left(D_{\text {it }}\right)$ have been determined with the help of $C-V$ and $G-V$ curves.

\subsection{MOS structure}

The MOS capacitor structure is shown in figure 1(a), it consists of metal-oxide-semiconductor regions. Electrical contacts are made to the metal gate and the back contact to the semiconductor. Accumulation occurs typically for negative voltages ( $p$-Si substrate), where the negative charge on the gate attracts holes from the substrate to the oxidesemiconductor interface. Depletion occurs for positive voltages; the positive charge on the gate pushes the mobile holes into the substrate, thereby depleting the semiconductor of the mobile carriers and leaving a negative charge in the space
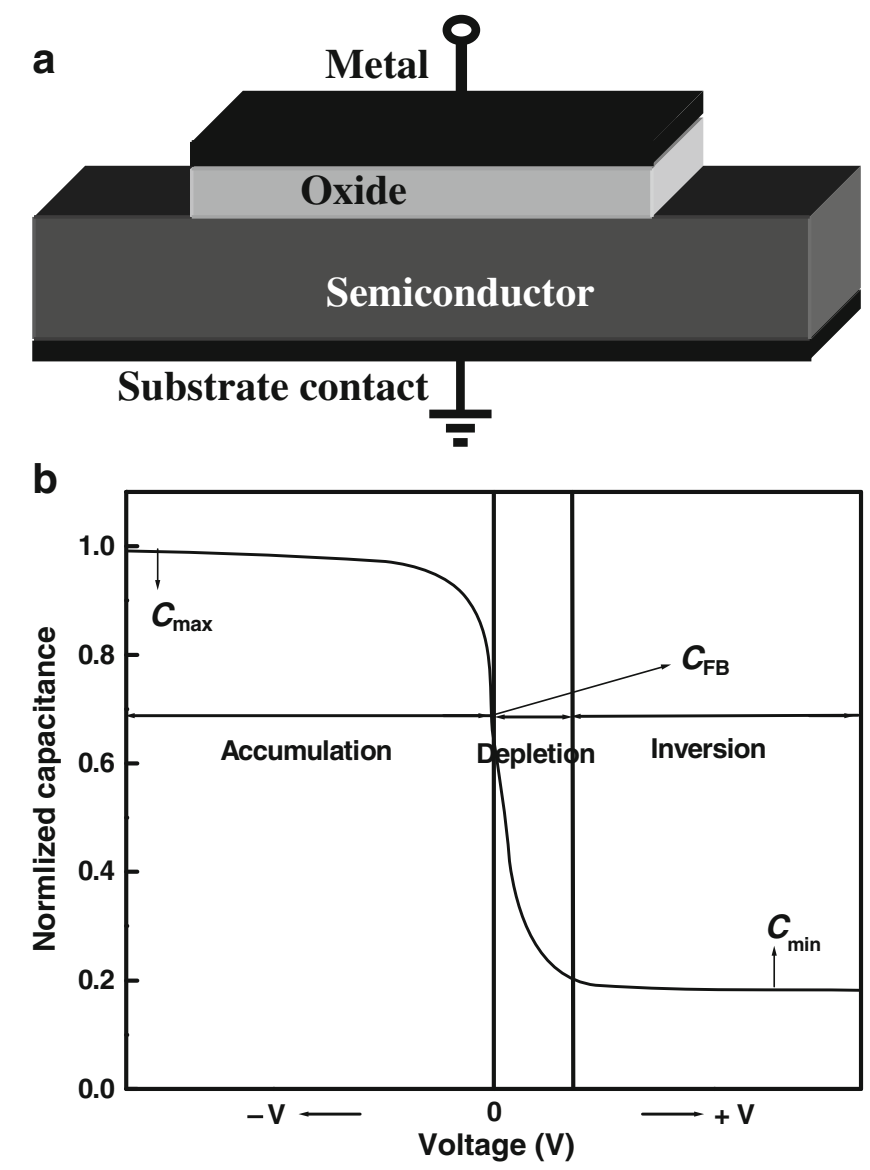

Figure 1. a. Cross section of MOS capacitor structure and b. $C-V$ characteristics of MOS structure at high frequencies.

charge region which is due to the ionized acceptor ions. The voltage separating the accumulation and depletion regime is referred to as the flatband voltage as shown in figure 1(b). Inversion occurs at more positive voltages which are larger than the threshold voltage. In addition to the depletion layer charge, a negatively charged inversion layer forms at the oxide-semiconductor interface.

\subsection{Concept of equivalent oxide thickness (EOT)}

The gate oxide thickness required for good MOSFET control actually depends on the capacitance of the film. Capacitance is given by

$$
C=k \varepsilon_{0} A / t_{\mathrm{ox}},
$$

where $k$ is the dielectric constant, $A$ the area and $t_{\mathrm{ox}}$ the thickness.

Silicon dioxide $\left(\mathrm{SiO}_{2}\right)$ has a $k$ value of $3 \cdot 9$, if an alternate material could be found with a higher $k$ value, then the same capacitance per unit area $A$ could be achieved with a physically thicker film and potentially lower leakage. Comparison 

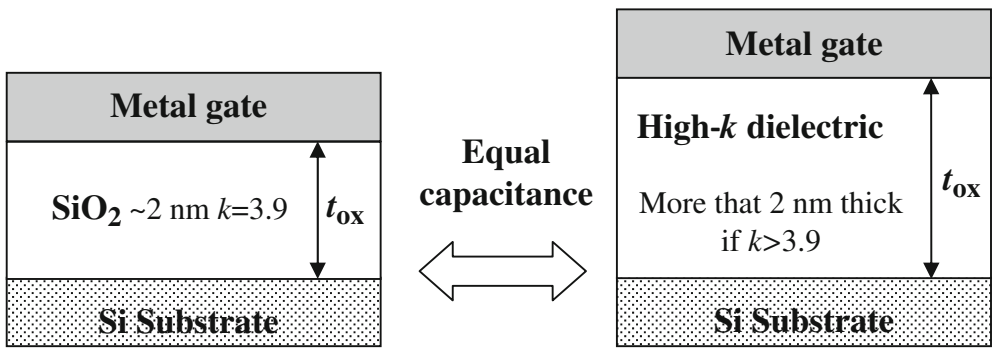

Figure 2. Comparison of gate dielectrics used in transistor gate stacks. Both structures result in same gate stack capacitance.

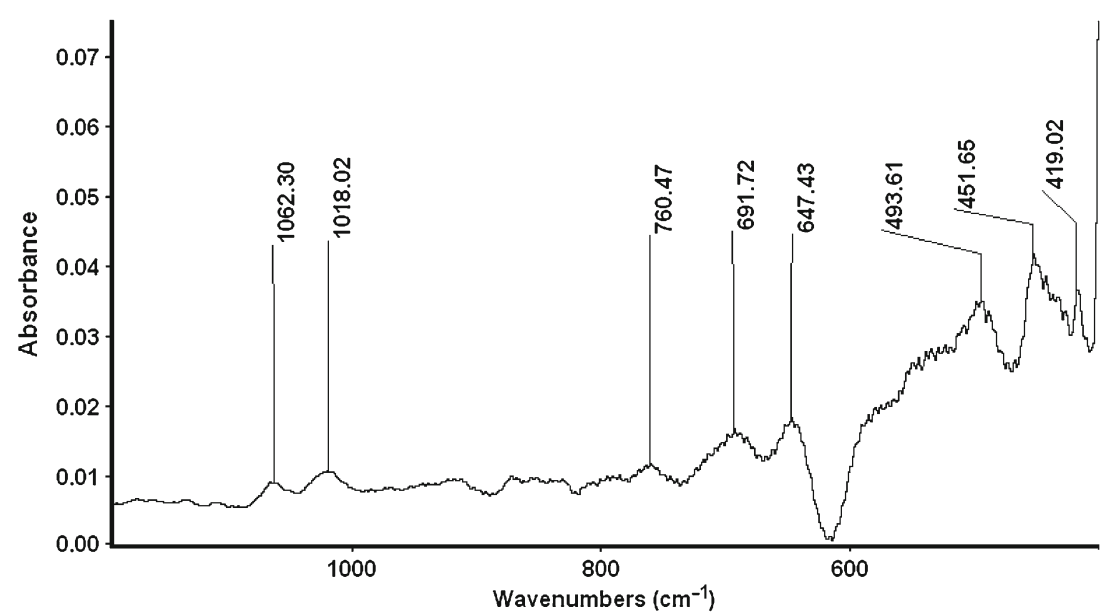

Figure 3. FTIR spectra of $\mathrm{CeO}_{2}$ film annealed at $400^{\circ} \mathrm{C}$.

of various films and thickness that would result is done using the concept of equivalent oxide thickness (EOT) (figure 2). EOT is given by:

$$
\mathrm{EOT}=\left(k_{\mathrm{SiO}_{2}} t_{\mathrm{ox}}\right) / k_{\mathrm{x}},
$$

where $k_{\mathrm{x}}$ is the $k$ value for the film of interest, $t_{\mathrm{ox}}$ the physical thickness of the film of interest and $k_{\mathrm{SiO}_{2}}$ the $k$ value of silicon dioxide. From (2), a film with a $k$ value of 7 could be almost twice as thick as a silicon dioxide film with a $k$ of 3.9 and still have the same control over MOSFET.

\section{Results and discussion}

\subsection{Ellipsometer}

Thickness and refractive index of the cerium dioxide thin film are measured with ellipsometer (Philips SD1000) at the visible wavelength of $632.8 \mathrm{~nm}$ using single point measurement technique. The measured average value of physical thickness is $5.56 \mathrm{~nm}$ and refractive index is 2.18 . The EOT determined for deposited film is $1.14 \mathrm{~nm}$. The measured value of refractive index is comparable to the (2.13-2.33) reported by Quah et al (2010) for $\mathrm{CeO}_{2}$ deposited by the metal-organic decomposition method (MOD).

\subsection{Fourier transform infrared spectroscopy (FTIR)}

Figure 3 shows FTIR spectra of the deposited cerium oxide thin film. The FTIR analysis was carried out to obtain information about chemical bonding characteristics. The spectrum is shown in the range of $400-1200 \mathrm{~cm}^{-1}$. The spectrum shows the existence of both $\mathrm{Ce}$ - and $\mathrm{Si}$-oxide phases. The peaks from $500-800 \mathrm{~cm}^{-1}$ are due to the presence of $\mathrm{Ce}-\mathrm{O}$ bond (Wang et al 2001). In the present spectra of the film, peak at $647.43 \mathrm{~cm}^{-1}$ is corresponding to $\mathrm{Ce}-\mathrm{O}$ bond, the $\mathrm{Si}-$ $\mathrm{O}$ bond appears at $1062.30 \mathrm{~cm}^{-1}$ and the broad $\mathrm{O}-\mathrm{H}$ bond has been detected at $3381 \mathrm{~cm}^{-1}$ (not shown) which may be due to the presence of moisture, however, it can be reduced by annealing the deposited $\mathrm{CeO}_{2}$ films at higher annealing temperatures. The presence of $\mathrm{Si}-\mathrm{O}$ bond shows existence of interfacial $\mathrm{SiO}_{2}$ between $\mathrm{Si}$ substrate and $\mathrm{CeO}_{2}$.

\section{$3.3 X R D$}

The crystal structure of the film is verified with X-ray diffraction (XRD). Figure 4 shows XRD spectra of $\mathrm{CeO}_{2}$ film annealed at $400{ }^{\circ} \mathrm{C}$. Mixed phase of $\mathrm{CeO}_{2}$ peaks with JCPDS card no. 034-0394 and 44-1001 were detected. Three diffraction peaks, which were ascribed to cubic phases of $\mathrm{CeO}_{2}$, were detected at (2 000$),\left(\begin{array}{lll}2 & 2 & 0\end{array}\right)$ and (3 111$)$ and one 


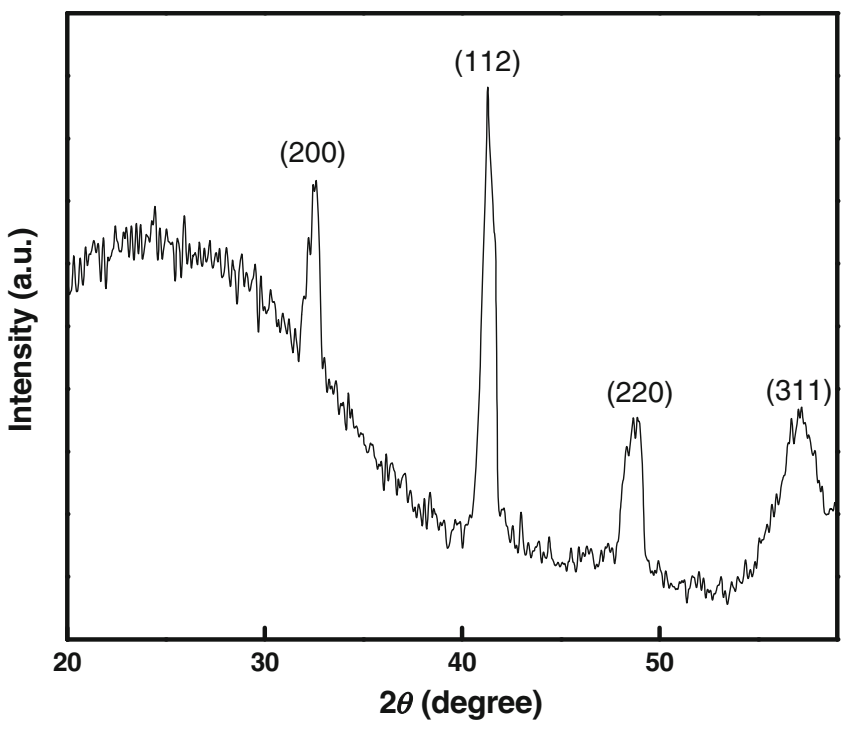

Figure 4. $\mathrm{XRD}$ spectra of $\mathrm{CeO}_{2}$ film annealed at $400^{\circ} \mathrm{C}$.

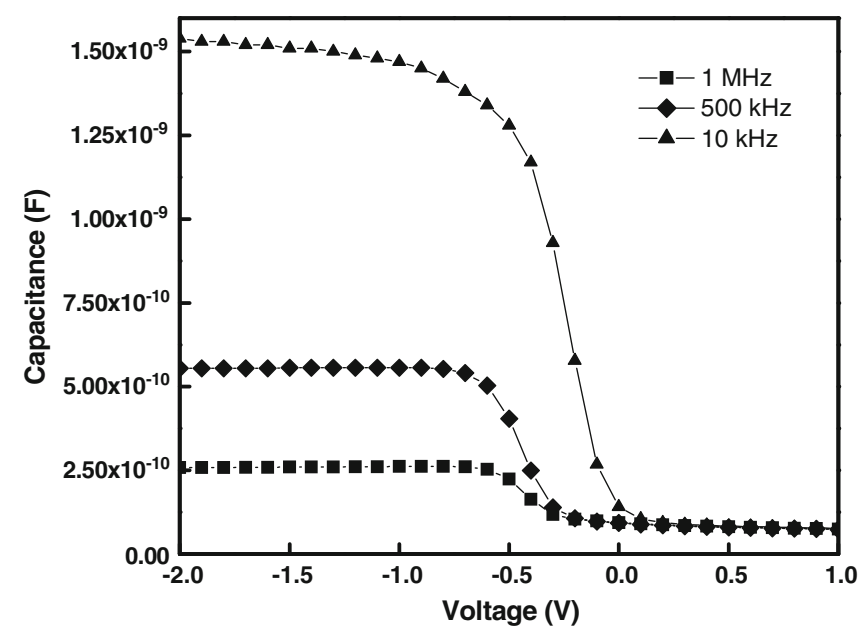

Figure 5. $C-V$ characteristics of $\mathrm{Al} / \mathrm{CeO}_{2} / \mathrm{Si} \mathrm{MOS}$ capacitor.

diffraction peak which was ascribed to hexagonal phase of $\mathrm{CeO}_{2}$ was detected at $\left(\begin{array}{lll}1 & 1 & 2\end{array}\right)$. These peaks are in well agreement with the $\mathrm{CeO}_{2}$ films deposited by MOD (Quah et al 2010). Diffraction plane of ( $\left.\begin{array}{lll}1 & 1 & 2\end{array}\right)$ reveals the maximum peak intensity as compared to other peaks. Hence it is considered that a preferred oriented (llll 112 ) plane is produced.

\section{$3.4 C-V$ and $G-V$ characteristics}

$\mathrm{Al} / \mathrm{CeO}_{2} / p-\mathrm{Si}$ MOS capacitor was characterized by the Agilent 4284A LCR meter for the measurements of electrical properties of the fabricated MOS structure at different frequencies. A typical $C-V$ characteristics curve of MOS structure is shown in figure 5. The dispersion observed in the accumulation region is due to the substrate series resistance, $R_{\mathrm{s}}$, which mainly affects the highfrequency $C-V$ curve. The $C-V$ curves are corrected for the

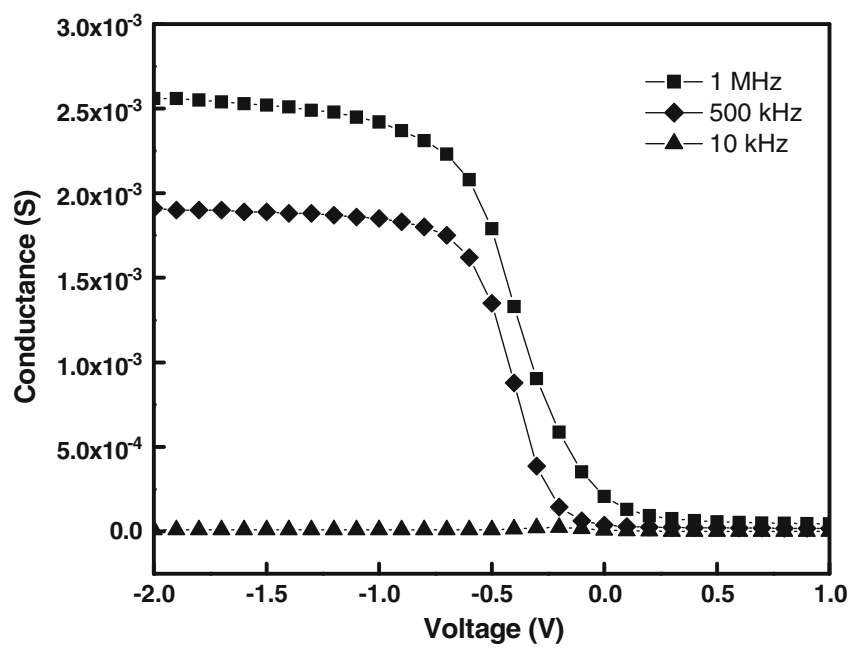

Figure 6. $G-V$ characteristics of $\mathrm{Al} / \mathrm{CeO}_{2} / \mathrm{Si} \mathrm{MOS}$ capacitor.

determination of the dielectric constant (Wu et al 2006). The dielectric constant determined from accumulation capacitance of $C-V$ curve obtained at measurement frequency of $1 \mathrm{MHz}$ is 18.92 . The determined $k$ value appears to be lower than the expected may be due to the growth of undesired $\mathrm{SiO}_{x}$ interface layer at the $\mathrm{CeO}_{2} / p$-Si interface upon high temperature treatment in an open air as observed in the FTIR spectra. The value of equivalent oxide thickness using dielectric constant of 18.92 and electrode area of $3.14 \times 10^{-4} \mathrm{~cm}^{2}$ is calculated as $1.14 \mathrm{~nm}$. There is a slightly negative shift $(0.3-0.5 \mathrm{~V})$ in the flat-band voltage $\left(V_{\mathrm{FB}}\right)$ observed from figure 5 due to the presence of positive effective oxide charges ( $\left.Q_{\text {eff }}\right)$ located in $\mathrm{CeO}_{2}$ thin film. The $Q_{\text {eff }}$ is found by using (3) and thus calculated as $7.69 \times 10^{12} \mathrm{~cm}^{-2}$ (Cheong et al 2008). The conductance-voltage $(G-V)$ measurement as shown in figure 6 , was employed to investigate the density of trapped charges at the $\mathrm{CeO}_{2} / \mathrm{Si}$ interface. The density of trapped charges $\left(D_{\mathrm{it}}\right)$ calculated from the Hill-Coleman method (Oulachgar et al 2007) using (4). The obtained values of $D_{\mathrm{it}}$ at $1 \mathrm{MHz}, 500$ and $10 \mathrm{kHz}$ are $1.40 \times 10^{13} \mathrm{eV}^{-1} \mathrm{~cm}^{-2}$, $2.00 \times 10^{13} \mathrm{eV}^{-1} \mathrm{~cm}^{-2}$ and $7.37 \times 10^{12} \mathrm{eV}^{-1} \mathrm{~cm}^{-2}$, respectively which can be further minimized by annealing the films in different ambient at higher temperatures. The obtained $D_{\text {it }}$ value appears to be higher as compared with others (Quah et al 2010, $2.5 \times 10^{12} \mathrm{eV}^{-1} \mathrm{~cm}^{-2}$ ) which may be due to the trapping of charges in $\mathrm{SiO}_{x}$ interfacial layer observed in the FTIR spectra.

$$
Q_{\mathrm{eff}}=\frac{\Delta V_{\mathrm{FB}} C_{\mathrm{ox}}}{q A},
$$

where $C_{\mathrm{ox}}$ is the oxide capacitance, $q$ the electronic charge, $A$ the electrode area and $\Delta V_{\mathrm{FB}}$ the flat band voltage shift.

$$
D_{\mathrm{it}}=\frac{2 \omega C_{\mathrm{ox}}^{2} G_{\max }}{q A\left\{G_{\max }^{2}+\omega^{2}\left[C_{\mathrm{ox}}-C_{\mathrm{m}}\left(G_{\max }\right)\right]^{2}\right\}},
$$

where $C_{\mathrm{m}}$ is the maximum capacitance, $G_{\max }$ the maximum conductance and $\omega$ the frequency. 


\section{Conclusions}

In this work, $\mathrm{CeO}_{2}$ thin film having a thickness of $5.56 \mathrm{~nm}$ was successfully deposited by the sol-gel technique on $p$-Si substrate. The dielectric constant value of the deposited $\mathrm{CeO}_{2}$ film is 18.92 and an equivalent oxide thickness is $1.14 \mathrm{~nm}$. The dielectric constant is observed to be lower than its ideal $(\sim 26)$ value due to the growth of low- $k$ interfacial layer of $\mathrm{SiO}_{x}$ as seen in FTIR spectra. The FTIR spectra confirms the deposition of $\mathrm{CeO}_{2}$ film. $\mathrm{CV}$ measurement showed negative shift in flat-band voltage and positive effective oxide charges. The value of $Q_{\text {eff }}$ determined to be $7.69 \times$ $10^{12} \mathrm{~cm}^{-2}$. From the aforementioned observations, deposited $\mathrm{CeO}_{2}$ thin films on $p$-Si can be promising alternative gate dielectric candidate for application in CMOS technology due to its higher dielectric constant and lower EOT.

\section{Acknowledgements}

The financial support from University Grants Commission (UGC), New Delhi, India, vide F. No. 36$181 / 2008$ (SR) and through SAP-DRS, phase-II program no. F.530/2/DRS/2010 (SAP-I) is greatly acknowledged.

\section{References}

Ami T and Suzuki M 1998 Mater. Sci. Eng. B54 84

Cheong K Y, Moon J H, Kim H J, Bahng W and Kim N-K 2008 J. Appl. Phys. 103084113

Guha S and Narayanan V 2009 Annu. Rev. Mater. Res. 39181

Gusev E P 2006 IBM J. Res. \& Dev. 50387

Gusev E P, Copel M, Cartier E, Baumvol I J R, Krug C and Gribelyuk M A 2000 Appl. Phys. Lett. 76176
Houssa M et al 2006 Mater. Sci. Eng. R51 37

Inoue T, Yamamoto Y, Koyama S, Suzuki S and Ueda Y 1990 Appl. Phys. Lett. 561332

Inoue T, Yamamoto Y and Satoh M 1999 Thin Solid Films 343594

Joumori S, Nakajima K, Suzuki M, Kimura K, Nishikawa Y, Matsushita D, Amaguchi T and Satou N 2004 Jpn J. Appl. Phys. 437881

Kang J F, Ziong G C, Lian G J and Han R Q 1998 Solid State Commun. 108225

Karakaya K, Zinine A, van Berkum J G M, Verheijen M A, Rittersma Z M, Rijnders G and Blank D H A 2006 J. Electrochem. Soc. 153 F233

Lee B H, Kang L, Nieh R, Qi W J and Lee C J 2000 Appl. Phys. Lett. 761926

Lim W F, Cheong K Y and Lockman Z 2011 Appl. Phys. A103 1067

Oulachgar E H, Aktik C, Scarlete M, Dostie S, Sowerby R and Gujrathi S 2007 Appl. Phys. Lett. 101084107

Quah H J, Cheong K Y, Hassan Z, Lockman Z, Jasni F A and Lim W F 2010 J. Electrochem. Soc. 157 H6

Quah H J, Lim W F, Cheong K Y, Hassan Z and Lockman Z 2011 J. Crystal Growth $\mathbf{3 2 6} 2$

Rathee D, Kumar M and Arya S K 2010 Int. J. Comp. Appl. 810

Wang S J, Xu S Y, You L P, Lim S L and Ong C K 2000 Semicond. Sci. Technol. 13362

Wang L P, Tang B Y, Huang N, Tian X B and Chiu P K 2001 Mater. Sci. Eng. A308 176

Wei-Hao W, Tsui B-Y, Chen M-C, Hou Y-T, Jin Y and Jao H-J 2006 Appl. Phys. Lett. 89162911

Wilk G D, Wallace R M and Anthony J M 2000 J. Appl. Phys. 87 484

Wilk G D, Wallace R M and Anthony J M 2001 J. Appl. Phys. 89 5243

Xiang W F, Lu H B, Yan L, Guo H L and Yang G Z 2003 J. Appl. Phys. 93533

Yu H Y, Li M F, Cho B J, Yeo C C, Joo M S, Zheng J Z and Ramanathan S 2002 Appl. Phys. Lett. 81376

Zhong H C, Heuss G, Misra V, Luan H, Lee C and Kwong D L 2001 Appl. Phys. Lett. 781134 